Revista Cógnito v.2:2 (2020) 203 - 217

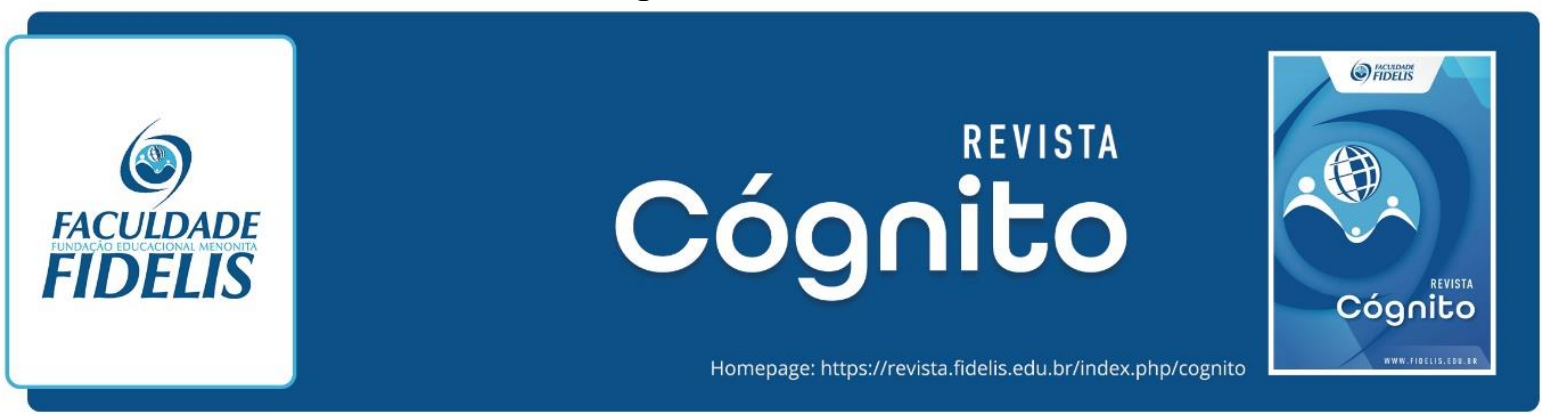

\title{
O EVANGELHO DE CRISTO E A GLOBALIZAÇÃO CULTURAL
}

\author{
THE GOSPEL OF CHRIST AND THE CULTURAL GLOBALIZATION
}

\section{Santareno Augusto Miranda ${ }^{1}$}

\begin{abstract}
RESUMO
A globalização da cultura tem sido percebida nas lentas mudanças relacionadas a costumes e hábitos de cada sociedade, o que tem sido inevitável, devido à pressão mundial por interação e integração. Nesse contexto, um dos grandes desafios missionários continua sendo a contextualização do Evangelho em um mundo em constante transformação. Assim, este artigo tem por objetivo apresentar reflexões sobre a Contextualização do Evangelho de Cristo e a Globalização Cultural. Para tanto, foi realizado um estudo bibliográfico com apresentação de algumas experiências culturais vivenciadas na infância e adolescência do autor em uma aldeia em Angola, bem como, no decorrer de sua vida missionária. As considerações finais enfatizam que em uma nova realidade que preza pela unificação de hábitos e costumes, via evolução tecnológica, o missionário deve estar atento para não colaborar com a globalização cultural, tendo real convicção de seu papel enquanto ator ativo no processo de evangelização.
\end{abstract}

PALAVRAS-CHAVE: Globalização Cultural, Contextualização do Evangelho, Angola, Missionário, Evangelização.

\section{ABSTRACT}

The globalization of culture has been noticed in slow changes related to customs and habits of each society, which has been inevitable due to the global pressure for interaction and integration. In this context, one of the major missionary challenges remains the contextualization of the Gospel in a changing world. Thus, this article aims to present reflections on the contextualization of the Gospel of Christ and the Cultural Globalization. Therefore, a biographic study was conducted, and it was presented some of the author's cultural experiences as a child and adolescent in a village in Angola, and the course of his missionary life. The final considerations emphasize that the missionary must be attentive not

\footnotetext{
${ }^{1}$ Mestre em Psicologia pela Universidade Tuiuti e Docente do curso de Bacharelado em Teologia da Faculdade Fidelis.santareno.miranda@fidelis.edu.br.
} 
to cooperate with the acculturation of the gospel of Christ through cultural globalization. Missionaries should seek real conviction of their role as an active player in the process of evangelization.

KEYWORDS: Cultural Globalization. Contextualization of the Gospel. Angola. Missionary. Evangelization.

\section{INTRODUÇÃO}

A transição dos séculos tem deixado profundas mudanças na forma com que o ser humano vem se relacionando. Essas mudanças são impulsionadas pela evolução tecnológica (conhecimento), sendo que seu acúmulo é principal indicativo de poder entre as nações, ao mesmo tempo em que mecanismo de proteção das economias mundiais.

Sabe-se que todo conhecimento humano passa por transformações em seu processo de comunicação. Considerada sua importância e que tem sido a ciência com maior impacto causado pela evolução tecnológica, tem-se então que a essência de cada sociedade, ou seja, sua forma de comunicação, tem se configurado em um processo de constante interação e mutação. Caminha-se então, para uma globalização da cultura via evolução tecnológica.

A globalização da cultura tem sido percebida nas lentas mudanças relacionadas a costumes e hábitos de cada sociedade, o que tem sido inevitável, devido à pressão mundial por interação e integração. Com isso, tem sido cada vez mais difícil preservar sociedades intactas em sua essência cultural.

A vivência na aldeia Maquimba, município de Ebo, cidade de Luanda em Angola, permite colaborar com algumas reflexões sobre quão desafiador é discutir sobre evangelho e cultura.

O contraste entre a cultura da infância e adolescência na aldeia em Luanda, com a realidade brasileira faz emergir questões que merecem ser discutidas, sobretudo ao serem confrontadas com o Evangelho de Cristo. Por essa razão, esse artigo tem por objetivo trazer à tona a difícil missão de levar a palavra de Deus a todas as nações e busca enfatizar o risco do Evangelho de Cristo sofrer aculturação via globalização cultural.

Compreender o evangelho e o processo de globalização da cultura é um passo importante para viver e anunciar este evangelho sem grandes conflitos. Portanto, um dos grandes desafios missionários continua sendo a contextualização do Evangelho em um mundo 
em constante transformação. Assim, este artigo tem por objetivo apresentar reflexões sobre a Contextualização do Evangelho de Cristo e a Globalização Cultural. Para tanto, foi realizado um estudo bibliográfico cuja principal fundamentação é a Bíblia Sagrada. Também são apresentadas algumas experiências culturais vivenciadas na infância e adolescência do autor em uma aldeia em Angola, bem como, no decorrer de sua vida missionária.

Por mais que o tema seja discutido, sabe-se que se trata de um assunto difícil de ser dissertado, ainda mais esgotado. Portanto, espera-se fornecer com esse estudo, reflexões que sirvam de orientações para ajudar no trabalho missionário.

\section{GLOBALIZAÇÃO CULTURAL}

Definir Cultura é um exercício exaustivo, de modo que a busca de um consenso tem sido difícil, sobretudo em um mundo que caminha para a integração das culturas via evolução tecnológica. Por esse motivo, os antropólogos têm encontrado dificuldades para definir de forma clara e definitiva o que é a cultura.

$\mathrm{Na}$ conceituação do tema, tem-se que "Cultura é um conjunto de sinais característicos do comportamento de uma camada social, linguagem, vestimenta, gestos, crenças, tradições tecnológicas, artísticas, mitos ou representações coletivas de um grupo social" (GRANDE ENCICLOPÉDIA LAROUSSE CULTURAL, 1998, p. 97). Assim, cultura pode ser entendida como uma forma de um grupo expressar a sua maneira de viver, o que crê, como trabalham, como se comunicam, como convivem entre si e com outros grupos diferentes.

Outra questão a ser assinalada é que "A cultura está intimamente ligada à linguagem e se expressa em provérbios, mitos, contos populares e diversas formas de arte, que constituem parte do equipamento mental de todos os membros de um grupo social" (LAUZANE, 1983, p. 9), assim, "o termo cultura designa os modos de agir, e o termo social ou sociedade designa o grupo de indivíduos que compartilham de um mesmo modo de agir” (LARAIA, 2000).

Se a cultura é um conjunto de formas de pensar, crer, comunicar e viver, ela é de suma importância, pois sem ela não haveria o desenvolvimento dos grupos sociais. Sem a cultura seria impossível haver convívio social na terra. Sem cultura não haveria a possibilidade de se comunicar e criar formas de expressão, não seria possível desenvolver trabalhos comunitários e, as trocas comerciais seriam inviabilizadas. 
A primeira referência de desenvolvimento de cultura humana pode ser extraída a partir da criação, com a formação do primeiro grupo social, ou seja: Adão e Eva. "Deus havia criado o homem, mas este estava só, então Deus fez a mulher para servir de companhia e idoneidade" (Gn 2:18).

Nesse ínterim, o homem recebeu a mulher com estas palavras: “[...] Esta, afinal, é osso dos meus ossos, carne da minha carne; chamar-se-á varoa, porquanto do varão foi tomada. Por isso, deixa o homem seu pai e sua mãe e se une à sua mulher, tornando os dois uma só carne" (Gn 2:23-24).

Adão e Eva, certamente desenvolveram uma forma de se comunicar, fundaram costumes, e uma maneira mútua de agir e pensar. Nessa ótica, pode-se inferir que a cultura é antiga, vem da criação e tem acompanhado a história do ser humano.

A cultura não é algo que pertence a um único indivíduo, mas a um grupo, portanto tem uma natureza coletiva. Uma pessoa sozinha não forma cultura. Mas $\mathrm{O}$ conjunto de pessoas é que formam ideias, formas de pensar, falar e viver. Na criação do mundo Deus viu que o homem estava só. Então Deus fez a mulher para o homem. O homem e a mulher, no Éden, desenvolveram sua própria cultura. Tudo o que fizeram baseava-se no que eles sabiam e entendiam um do outro, sem conflitos culturais.

Essencialmente o homem não foi feito para viver sozinho, mas, em sociedade e amparado, protegido e ajudado pelo outro. Nessa relação ocorre a compreensão mútua, fator primordial no desenvolvimento da cultura. Do contrário o convívio seria difícil ou impossível, razão pela qual, a cultura é fator essencial para a sobrevivência de um grupo.

Por esse motivo a gêneses humana compreende Homens e mulheres em sua existência unificada. É na participação em uma cultura que o homem identifica o sentido de pertencer a algo. "A cultura dá um sentido de segurança, de identidade, de dignidade, de ser parte de um todo maior e de partilhar a vida de gerações anteriores e também das expectativas da sociedade com respeito a seu próprio futuro" (LAUZANE, 1983, p. 10).

A cultura cria a noção de participação coletiva, e nessa relação ocorre a aceitação dos direitos e responsabilidades. "Os direitos asseguram a inclusão, a liberdade de agir, falar e fazer algo, enquanto, a responsabilidade, está relacionada, a estes direitos, de agir sem ferir a cultura, pois do contrário, consequências deverão ser tomadas, como a coerção moral por exemplo" (LAUZANE, 1983, p. 13). Nesse contexto, a cultura está a favor de todos no grupo 
social e não apenas a favor de um indivíduo. Este fator de direito e responsabilidade cultural, acaba preservando a cultura para as gerações posteriores.

Com a globalização cultural via evolução tecnológica, muitos grupos sociais têm cedido parte ou toda sua cultura a uma tendência universal. No campo missionário esse processo de aculturação tem sido percebido de forma externa. Aldeias com celulares, computadores e outros aparatos tecnológicos, tem mesclado tradições a uma nova e inevitável realidade global. Se por um lado ganha-se em comunicação em outro se perde, e muito, com a absorção ou integração cultural.

No caso da aldeia Maquimba em Ebo ${ }^{2}$, pode-se destacar que a realidade da década de 2015 é muito diferente dos anos de 1950. A evolução tecnológica, enquanto fio condutor trouxe consigo não apenas transformações externas, mas profundamente internas.

Ocorre que aprender os elementos culturais da aldeia não é suficiente para alcançar a compreensão desse povo em relação ao Evangelho de Cristo. A integração de traços tecnológicos na frágil cultura Maquimba, em Ebo, parece refletir um movimento global tensionado pelo desejo ao acúmulo de capital. Nessa realidade compreende-se que o homem se perde em suas relações humanas.

Onde havia amor puro à natureza, se observa o desejo pelo material. Onde havia a reunião familiar, ocorre a troca desses valores por tendências pré-concebidas de um novo mundo, de uma família ideal, de um novo homem.

A palavra ressalta que com a queda do Homem a cultura foi manchada pelo pecado, comprometendo as suas relações humanas. E essa tem sido a realidade da aldeia Maquimba em Ebo, que mesmo distante dos princípios cristãos, vem perdendo a guerra para uma cultura universal que lhe empurra para um novo modelo cultural de integração.

Sem compreender a relação entre sua cultura e o mundo, a aldeia vem perdendo seus traços culturais, e nessa transformação, a resistência ao evangelho, ou melhor, a seus princípios, tem sido evidente. Isso tem ocorrido por dois fatores: primeiramente porque ao levar sua cultura para o contexto em que se leva o evangelho, o missionário tende a enfatizar mais sua "aparência" que o próprio evangelho, influenciando sobremaneira a cultura local. Além disso, muitas vezes a cultura do povo passa a ser assimilada ao invés de absorver, a essência do evangelho, em um processo de aculturação.

\footnotetext{
${ }^{2}$ Maquimba Ebo é a aldeia em que nasceu Santareno Augusto Miranda
} 
Cabe salientar que o evangelho deve avaliar a cultura, e os seus valores morais, para depois buscar uma ponte de comunicação e encarnação do evangelho. Caso o missionário procure contextualizar o evangelho sem estas observações, correrá o risco de o evangelho assimilar um valor cultural que seja antibíblico, portanto, contra a vontade de Deus para todo o ser humano, de modo que ao invés de libertar o homem, continuará escravizando-o.

A aldeia, essencialmente possui seus valores históricos, logo, conhecê-los tornaria mais fácil a introdução ou transformação pela palavra de Deus. Ocorre que a aculturação fez com que os valores culturais da aldeia, sofressem continua influência da nova sociedade universal. Com isso, muito habitante tem adquirido hábitos, costumes e valores diferentes de sua cultura natal, criando, com isso, um novo padrão de compreensão de mundo, de valores, inclusive do Evangelho de Cristo.

É importante frisar que toda cultura tem elementos, fatores que comprometem o evangelho, ao mesmo tempo em que nenhuma cultura é superior a outra, ou seja, a cultura do missionário, não é superior a cultura do povo a quem leva o evangelho. Portanto, conforme bem explica Nicholls (2013) “o evangelho não pressupõe a superioridade de qualquer cultura sobre outra, mas sim, avalia todas as culturas de acordo com seus próprios critérios de verdade e justiça, e insiste nos absolutos morais em cada cultura".

A título de ilustração, no contexto africano, o conceito de liderar, é um conceito de domínio, é uma oportunidade de dominar os outros. Assim, o líder pode fazer o que quiser, mesmo que esteja errado, sendo que os súditos não deverão questionar, nem se opor a esta liderança.

Este tipo de liderança dominadora tende a se manter na administração da igreja, em muitos países africanos. O líder eclesiástico, muitas vezes age como um líder pagão. Ele pede reverencia ao entrar no templo na hora do culto, a sua cadeira no templo é exclusiva, ninguém pode assentar na mesma sem o consentimento do líder, de modo que quem fizer isso poderá ser punido com algumas restrições na igreja, como por exemplo, não participar da comunhão da ceia.

O povo obedece ao líder, porque a cultura tem maior influência no povo, e o evangelho nesta cultura assimilou esta forma cultural. O estilo de liderança Bíblico é de serviço, o líder tem que servir. Nestas culturas africanas o líder é servido. Por isso é tão comum nessa nação, as lutas de poder, a hierarquismo na igreja. 
O líder eclesiástico é adorado como é adorado o "Soba", Pajé, que é o líder de uma aldeia. Neste caso, ocorre o sincretismo ${ }^{3}$ cultural.

Essa condição, tem tornado o trabalho dos missionários cada vez mais difíceis, exigindo maior conhecimento, comunhão, e entendimento dos princípios da palavra de Deus. Assim, o missionário precisa conhecer a si mesmo e ao povo a quem vai levar o evangelho. A falta deste conhecimento tem servido para uma exportação de seus conceitos culturais, dificultando o processo de contextualização do evangelho.

Por fim, o missionário precisa conhecer a sua cultura, a do povo, o evangelho e, suas vertentes centrais, para que saiba como encarnar o evangelho na cultura, sem que este evangelho perca a sua essência e as suas vertentes centrais.

\section{A RELAÇÃO ENTRE O EVANGELHO E A CULTURA}

Evangelho é boa nova e boa notícia. Notícia recebida com alegria, e o termo refere-se à tradução da palavra grega "euangelion”, que significa, "notícias boas, alegres, felizes e jubilosas, que enchem de gozo o coração humano, levando a pessoa a cantar, dançar e pular de alegria” (ELWELL, 2009, p. 74).

O Apostolo Paulo a define da seguinte forma:

Paulo servo de Jesus Cristo, separado para o evangelho de Deus,... prometido por intermédio dos seus profetas nas Sagradas Escrituras, com respeito a seu Filho, o qual, segundo a carne, veio da descendência de Davi, e foi designado Filho de Deus, Jesus Cristo, nosso Senhor (Rm 1:1-6).

O evangelho não é uma notícia de procedência humana, o seu portador pode ser humano, mas ela é uma notícia divina, vem de Deus para o ser humano. É uma notícia que, segundo Paulo anuncia a graça de Deus, a libertação do pecado, o serviço a Deus por amor a ele, a fé que é pela obediência daqueles que creem neste evangelho, o pertencimento a Cristo por meio da obediência por fé.

\footnotetext{
3 “O sincretismo cultural adota duas formas. Pode resultar de uma tentativa entusiasta de traduzir a fé cristã por meio de usar acriticamente os símbolos e as práticas religiosas da cultura receptora, tendo como resultado uma fusão de crenças e práticas cristãs e pagãs" (NICHOLLS, 2013).
} 
O evangelho é de Deus, é Jesus Cristo. Paulo ainda diz que "o evangelho é o poder de Deus para salvação de todo aquele que crê, primeiro do Judeu, depois do grego" (Rm 1:16). O poder do evangelho está no fato de ser a única fonte que liberta o homem do pecado, da morte e do juízo de Deus. Todo homem e mulher que almeja a sua libertação do pecado deve aceitar este evangelho, que é boa nova, e é poder de Deus.

O homem em suas relações humanas tem manifestado a natureza pecaminosa, que o impede por vezes de ter relações sadias com o próximo. Nesse contexto, o evangelho tem a missão de permear as diferentes culturas a fim de purificar essa relação.

Com base nisso, nesse capítulo será apresentada algumas reflexões sobre a compreensão relativa à relação entre o evangelho e a cultura, enfatizando como deve ser o papel do portador do evangelho ao anunciar o evangelho de Cristo, sem que isso gere conflitos à cultura.

\subsection{CONTEXTUALIZAR SEM FERIR O EVANGELHO}

Sendo o evangelho a boa notícia, sabe-se que toda notícia tem a sua finalidade, e neste caso também o tem o evangelho de Cristo. Cabe ressaltar que o propósito do evangelho de Deus não é apenas trazer alegria.

O apóstolo Paulo a chama de "Salvação". O evangelho de Deus traz salvação para aquele que o recebe "não me envergonho do evangelho, porque é poder de Deus para salvação de todo aquele que crê, primeiro do Judeu, depois do grego" (Rm:1-16). A finalidade do evangelho é salvar o homem dos seus pecados. "Ela dará à luz um filho e lhe porás o nome de Jesus, porque ele salvará o seu povo dos pecados deles” (Mt 1.21).

Salvar o povo dos pecados, esta é a finalidade do evangelho de Deus. E esta salvação torna possível a aproximação do homem a Deus. Como o apóstolo Paulo cita em Romanos ( $\operatorname{Rm} 1: 16)$, o evangelho não tem barreiras culturais ou raciais. É para todo aquele que crê no evangelho.

Deus, por meio do evangelho, liberta o homem do domínio do Diabo e do pecado, a fim de que tenha vida em abundância e viva eternamente. "Ele nos libertou do império das trevas e nos transportou para o reino do filho do seu amor, no qual temos a redenção, a 
remissão dos pecados" ( $\mathrm{Cl}$ 1:13-14); "O ladrão vem somente para roubar, matar e destruir; eu vim para que tenham vida e a tenham em abundância" (Jó 10:10). O evangelho de Deus traz vida e vida em abundância. Sendo Deus o doador da vida, Ele dá vida aqueles que creem no evangelho.

Levar o evangelho a todas as culturas tem se tornado uma missão cada vez mais complexa. Em um cenário de profundas transformações nos hábitos e costumes das civilizações rumo a uma unificação cultural, faz-se necessário compreender além dos traços culturais, suas formas de expressão, ou seja, seu modo de pensar, agir e compreender as relações humanas.

Assim, a compreensão do comportamento cultural é importante, pois, na maioria dos casos a mensagem do evangelho requer uma postura transcultural, o que normalmente gera conflitos. Dessa forma, deve-se buscar compreender a cultura do grupo social para o qual se dirige, para que então seja possível estabelecer mecanismos para comunicar o evangelho.

Neste processo de contextualização, pode-se citar o apóstolo Paulo, por sua sabedoria e sensibilidade em pregar o evangelho de Cristo em diferentes contextos culturais. Sendo Judeu, Paulo foi separado para ser apóstolo aos gentios, o que lhe rendeu muitas situações adversas em suas viagens missionárias. Seu êxito pode ser atribuído à motivação ao amor a Deus e ao povo a quem ele desejava anunciar o evangelho de Deus. Seus conflitos teológicos e culturais, sua dependência a Deus e, sobretudo, seu discernimento em relação à fé, ao evangelho e ao que não é essencial, fornecem um referencial de como entrar numa cultura, viver nela e encarnar a mensagem do evangelho.

Paulo era Judeu, e cresceu aos pés de Gamaliel, Rabi, mestre em Israel. Fariseu convicto, sua característica mais marcante até então era o zelo à religião, portanto, era perseguidor dos cristãos que pregavam o evangelho de Deus. Conforme a palavra:

E Saulo consentia na sua morte. Naquele dia levantou-se grande perseguição contra a igreja em Jerusalém; e todos, exceto aos apóstolos foram dispersos pelas regiões da judeia e Samaria. Saulo, porém, assolava a igreja, entrando pelas casas e, arrastando homens e mulheres, encerrava-os no cárcere (At 8:1,3).

Foi no caminho para Damasco, cujo objetivo da viagem era prender, e se possível matar alguns cristãos, que teve seu encontro com Jesus Cristo. Por meio de uma visão, manteve um diálogo com Cristo: 
E Saulo, respirando ainda ameaças e mortes contra os discípulos do Senhor, dirigiuse ao sumo sacerdote. E pediu-lhe cartas para Damasco, para as sinagogas, a fim de que, se encontrasse alguns deste Caminho, quer homens quer mulheres, os conduzisse presos a Jerusalém. E, indo no caminho, aconteceu que, chegando perto de Damasco, subitamente o cercou um resplendor de luz do céu (At 9:1-3).

Nesse momento, Saulo teve o encontro com o Senhor Jesus. Seguiu viagem para Damasco onde foi recebido pelo discípulo do Senhor, Ananias e teve o seu comissionamento. "Mas o Senhor lhe disse: Vai, pois este é para mim um instrumento escolhido para levar o meu nome perante os gentios, perante reis, bem como perante os filhos de Israel" (At 9:15).

Assim, Paulo é vocacionado como apóstolo aos gentios, reis e perante os israelitas. O seu ministério se dá nestes contextos diferentes, porém muito atuante e eficaz. Paulo saiu para pregar o evangelho, seguindo as ordens do Senhor. Foi primeiramente aos israelitas. "Procedi, para com os judeus, como Judeu, a fim de ganhar os judeus, para os que vivem sob o regime da lei, como se eu mesmo assim vivesse, para ganhar os que vivem debaixo da lei, embora não esteja eu debaixo da lei” (I Cor 9:20). O procedimento de Paulo é buscar dentro da lei e da cultura judaica, uma forma positiva que pudesse ajudá-lo a contextualizar o evangelho. $\mathrm{O}$ fazer-se judeu, é viver no seio deles, buscar uma reflexão como se fosse judeu praticante da lei.

A preocupação de Paulo, portanto não era apenas para não servir de escândalo, mas também de encontrar no meio desta cultura um aspecto positivo no qual ele pudesse apoiar sua mensagem evangelística. Dessa forma, Paulo encarnou, viveu como judeu que vive debaixo da lei mesmo que ele não estava debaixo da lei. É o fator de viver numa cultura, sem que esta condição domine a essência da reflexão, mas uma estratégia para a contextualização do evangelho.

Cabe salientar que o princípio que Paulo toma para se contextualizar entre os judeus, parece ser o mesmo, entretanto não é. Se com os judeus ele procurava ser como eles, aos gentios se comportava como se ele não tivesse a lei dos judeus. "Aos sem lei, como se eu mesmo o fosse não estando sem lei para com Deus, mas debaixo da lei de Cristo, para ganhar os que vivem fora do regime da lei" (I Cor 9:21). Aos judeus, Paulo se comporta como se fosse como eles, embora não estando debaixo da lei. Paulo fala a língua deles, mas não usa os seus costumes. Para os gentios a vertente é outra. Paulo se comporta como alguém que não tem lei judaica, mas tendo a lei de Cristo. Paulo vive entre os gentios e o seu comportamento, é resultado de uma disposição de encarnação. Pois não é apenas o evangelho que tem que se encarnar, mas também o seu portador. 
Nesse contexto, tem-se na missão de Paulo a referência de que é possível contextualizar sem ferir o evangelho. Entretanto, deve-se ressaltar que aquele que leva o evangelho, assim como Paulo, deve viver como o povo a quem vai transmitir o evangelho, falar a sua língua, comer a sua comida, mas no que concerne a lei de Deus, aos valores morais, o missionário deve avaliá-los com os valores do evangelho, lembrando sempre que influencia e pode ser influenciado nessa missão. Paulo esqueceu a lei judaica, mas não esqueceu a lei de Cristo.

Assim como Paulo, todo missionário que se dedica à mensagem de salvação pagará um alto preço, muitas vezes com sua saúde, conflitos pessoais e familiares e até a morte, ao se entregar ao evangelho de Deus.

\subsection{CONTEXTUALIZAR SEM FERIR A CULTURA}

Assim como existe a dificuldade de contextualizar o evangelho numa cultura, o oposto também é verdadeiro. Quando se insere o evangelho numa cultura, é inevitável que essa cultura seja influenciada, sobretudo em virtude da necessidade de se abandonar certas práticas culturais que serviam para a unidade do povo.

A título de ilustração, em algumas aldeias de Angola, nos meses de Junho a Agosto, período de colheita, o povo faz Jangos (fogueiras), uma prática que reúne todas as noites, adultos, jovens e crianças. Nessa ocasião, os habitantes da aldeia compartilham a colheita com os vizinhos, de modo que cada um traz o que produziu e, prepara para a festa. A reunião é animada com hinos compostos pelos antepassados, que falam sobre unidade e fraternidade, embalados ao som do atabaque, instrumento típico da África.

Ocorre que alguns missionários, em virtude de não conhecerem a essência desse evento cultural, passaram a associar essa tradicional festividade angolana à uma prática pagã, passando a denominá-la como "festa da carne". Com isso, passaram a proibir os crentes de fazerem parte destas reuniões, sob a justificativa de que os angolanos não só tocam atabaque, como também dançam na presença de não-crentes.

O resultado desse equívoco é que aos poucos a cultura foi deixando de ser preservada, comprometendo com isso, a concepção de unidade e a fraternidade nestas aldeias. Aos poucos 
as novas gerações encontraram dificuldades em assimilar a cultura, cuja consequência foi a separação entre o povo.

Toda cultura tem formas que podem estar dentro dos padrões Bíblicos, como também pode ter formas culturais que podem ser antibíblicos. Cabe ao missionário, procurar conviver, conhecer a cultura, e buscar nela estas formas que podem ajudá-lo a contextualizar o evangelho, sem desvalorizar a cultura do povo. Assim, todo missionário deve compreender que ao contextualizar, não só o evangelho pode ser comprometido, mas a cultura também. Esta tarefa é importante mais muito difícil de ser trabalhada e compreendida.

É importante ter em mente que "O evangelho não pressupõe a superioridade de qualquer cultura sobre a outra, mas sim, avalia todas as culturas de acordo com seus próprios critérios de verdade e justiça, e insiste nos absolutos morais em cada cultura" (STEUERNAGEL, 1993). Ou seja, não deve ser pressuposto do evangelho a unificação da cultura, mas a adoração em espírito e em verdade.

Por esse motivo, é importante lembrar que:

O dogmatismo e militância exibidos pelo cristianismo missionário, fizeram com que o evangelho de Jesus Cristo pareça ser negativo e exclusivo não somente no que diz respeito às demais expressões culturais asiáticas e africanas. Parece que quanto mais for dogmático o cristão, tanto melhor se tornaria como missionário ou evangelista. Um dos resultados infelizes deste tipo de reação exagerada é a incapacidade de distinguir entre a teologia bíblica e a teologia ocidental (NICHOLLS, 2013, p. 26).

Dessa forma, os missionários que tiveram esta visão dogmática exportaram a sua cultura para outras culturas. Não tiveram o cuidado de separar a sua teologia, da teologia bíblica e a devida aplicação à cultura onde levaram o evangelho. O resultado é uma colonização evangélica. Um exemplo disto é a grande família Norte - americana, que no passado mandou muitos missionários a América do Sul e outros continentes. A sua prática missiológica, foi em grande parte dominada pela sua cultura dominadora.

Em sua maioria a família missionária norte-americana deste século, não fez a necessária autocrítica do império que ajudava a encarnar, a fim de que sua prática missionária pudesse ter um cheiro de independência crítica e o evangelho que procurava proclamar pudesse adquirir, com mais facilidade e mais rapidamente, um sabor local (STEUERNAGEL, 1993, p. 54).

Os povos evangelizados por estes missionários, muitas vezes acabaram assumindo comportamentos, e conceitos dogmáticos norte-americanos. Suas formas culturais e raízes 
culturais foram ignorados ou esquecidos, colocando o missionário e seus conceitos culturais como superiores a cultura local. Tem-se então, uma globalização cultural.

Com base no exposto, tem-se que é possível contextualizar sem ferir a cultura, entretanto, o missionário não pode ser o objeto de admiração excessiva do povo, nem tampouco a ponte de relacionamento e contextualização do evangelho, mas sim, o evangelho e a cultura do povo deve ser o centro do trabalho missionário, cujo caminho é a encarnação cultural.

Sugere-se então que o missionário deve primeiramente passar um tempo na cultura, na dependência de Deus, assimilar a cultura local, fazer leitura e avaliação da história do povo, com a ajuda da teologia bíblica. Esse momento de encarnação da cultura, ajudará o missionário a ter um novo olhar para a cultura ao redor, e lhe guiará a criar formas adequadas para anunciar a Cristo de forma compreensível ao povo da cultura local.

\subsection{RELAÇÃO ENTRE O EVANGELHO E A CULTURA}

Não é possível falar de cultura e do evangelho sem que primeiramente se entenda o que permeia o evangelho e a cultura.

O evangelho é encarnado. A fé cristã não é mitológica, mas ela se dá num tempo e espaço. Aliado a isso, a história e a geografia fazem parte do currículo da fé. Assim, o Evangelho é a transcendência numa embalagem da imanência.

O evangelho é temporal porque vem de Deus, mas ele é introduzido no Cronos, no nosso tempo, no aqui e agora. É assim que ele faz parte de tudo, inclusive da cultura. Portanto, não existem fronteiras geográficas, culturais, raciais ou sociais. É Deus falando, e Jesus encarnado, portanto, o verbo se encarnou.

Nesse contexto, a cultura como processo antropológico humano também sofreu os efeitos da queda do homem, mas nesta queda existe um desejo, um vazio de todo o ser humano pela transcendência, pelo divino, em maior ou menor escala.

Por esse motivo, todas as culturas possuem formas positivas como veículo da encarnação do evangelho. A própria Bíblia se dá dentro de uma cultura, com suas expressões, umas positivas e outras negativas. Neste caso, a Bíblia vive nesta tensão de ser universal e ao 
mesmo tempo moderável, adaptável numa cultura. Portanto, a cultura está a serviço do evangelho.

\section{CONCLUSÃO}

A relação entre o evangelho e a cultura, é algo que caminha com cada cristão, de modo que em qualquer cultura, existe este desafio.

A Bíblia mostra como Paulo. que viveu em contextos culturais diferentes. soube trabalhar esta relação sem grandes conflitos. Ele comeu com os gentios, falou a língua deles, viveu entre eles, isto vice e versa, tanto aos gentios como aos judeus. Portanto, a partir da referência de vida de Paulo, pode-se afirmar que é possível contextualizar sem ferir o evangelho, bem como, contextualizar sem ferir a cultura.

Em uma nova realidade que preza pela unificação de hábitos e costumes, via evolução tecnológica, o missionário deve estar atento para não colaborar com a globalização cultural, tendo real convicção de seu papel enquanto ator ativo no processo de evangelização.

A fé é cultural, ela não refletirá a vontade de Deus se ela não for trazida para as pessoas dentro de sua história. Este processo é vital para o impacto da boa nova. Pois o evangelho sem contextualização é apenas uma transmissão de um mito.

O grande desafio começa pela conversão. "Uma conversão radical a Cristo produz uma hermenêutica radicalmente nova" (NICHOLLS, 2013). O desafio de contextualizar o evangelho deve caminhar com o círculo hermenêutico. O missionário deve fazer sempre a leitura da sua história, a realidade do valor central do evangelho e o contexto da cultura onde estiver.

\section{REFERÊNCIAS}

ALMEIDA, João Ferreira de. Bíblia Sagrada. 17. ed. São Paulo: Edições Vida Nova, 1998. Bíblia Sagrada. 2. ed. São Paulo: Sociedade Bíblica do Brasil, 2001.

ELWELL, A. Walter. Enciclopédia histórico teológica da igreja cristã. São Paulo: Edições Vida Nova, 2009.

ENCICLOPÉDIA, Grande. Larousse Cultural. 2.ed São Paulo: Nova Cultura, 1998. 
LARAIA. Roque de Barros. Cultura: um conceito antropológico. Rio de Janeiro: Jorge Zahar, 2000.

LAUZANE (Série). O Evangelho e a cultura. São Paulo: Aliança Bíblica Universitária, 1983.

NICHOLLS, J. Bruce. Contextualização: uma teologia do evangelho e cultura. São Paulo: Edições Vida Nova, 2013.

STEUERNAGEL, Valdir. Obediência missionária e prática histórica. São Paulo: Aliança Bíblica Universitária, 1993. 